\title{
MicroRNA-139 suppresses hepatocellular carcinoma cell proliferation and migration by directly targeting Topoisomerase I
}

\author{
PENGFEI ZHANG ${ }^{1 *}$, JIKAI YIN $^{1 *}$, LIJUAN YUAN ${ }^{1}$, QING WANG ${ }^{1}$, XILIN DU $^{1}$, RUI DONG ${ }^{1}$, \\ CHENGGUO WANG ${ }^{1}$, QIANGSHAN BAI ${ }^{1}$, LING JI ${ }^{2}$, GUIZHI ZHANG ${ }^{3}$ and JIANGUO LU ${ }^{1}$
}

Departments of ${ }^{1}$ General Surgery and ${ }^{2}$ Orthopedics, Tangdu Hospital of The Fourth Military Medical University, Xi'an, Shaanxi 710038; ${ }^{3}$ Department of Liver Disease, The Third People's Hospital, Linfen, Shanxi 041000, P.R. China

Received July 14, 2017; Accepted February 1, 2018

DOI: $10.3892 / \mathrm{ol} .2018 .9746$

\begin{abstract}
RNAs (miRNAs) have been determined to be associated with cancer progression and metastasis. Mir-139 is located on 11q13.4 and exhibits anti-oncogenic and anti-metastatic activity in human cancers. It is downregulated in various malignant tumor types. In the present study, the potential functions and targets of miR-139 in hepatocellular carcinoma (HCC) were explored. Using a combinational analysis of four miRNA target prediction tools and biological experiments, it was determined that Topoisomerase I (TOPI) is a direct target of miR-139 in HCC. Several traditional topoisomerase inhibitors have demonstrated anticancer activity, but their side effects outnumbered their anticancer potential. The present study determined that overexpression of miR-139 significantly inhibits HCC cell proliferation $(\mathrm{P}<0.05)$ and migration $(\mathrm{P}<0.05)$, which is largely due to TOP1 downregulation. The present study indicated that miR-139 exerts a tumor-suppressive effect during hepatocarcinogenesis via the suppression of expression of TOP1; therefore, miR-139 is a promising target for the treatment of HCC.
\end{abstract}

\section{Introduction}

Hepatocellular carcinoma (HCC) is one of the most prevalent and mortality-associated cancer types in developing and developed countries and accounts for $70-90 \%$ of primary liver cancer cases (1). Despite numerous years of basic and clinical research on $\mathrm{HCC}$, the 5-year survival rate still remains at $\sim 7 \%$ (2). An alternative approach for addressing the poor survival problem may rely on discovering novel targets for

Correspondence to: Dr Jianguo Lu, Department of General Surgery, Tangdu Hospital of The Fourth Military Medical University, 569 Xinsi Road, Xi'an, Shaanxi 710038, P.R. China

E-mail: lujguo@hotmail.com

*Contributed equally

Key words: microRNA, miR-139, hepatocellular carcinoma, Topoisomerase I, proliferation, migration treatment. Hepatocarcinogenesis is a slow and complicated process that includes genomic changes that progressively alter the hepatocellular phenotype to produce abnormal cellular intermediates, finally resulting in HCC (3); however, the understanding of the underlying molecular mechanisms that drive hepatocarcinogenesis is still in its infancy. In the past 15 years, non-coding RNAs, particularly microRNAs (miRNAs), have received considerable attention regarding an elucidation of the molecular pathogenesis of cancer (4). Through recognizing the seed sequences in the 3'-untranslated region (3'-UTR) of target mRNAs, each miRNA has the ability to regulate the expression of numerous genes (5); therefore, miRNAs are frequently considered to efficiently coordinate and regulate multiple signaling pathways and biological processes in human diseases, particularly in cancers (5). Thus far, accumulating evidence has indicated that an abnormal miRNA expression profile is a hallmark of malignancies, including HCC $(6,7)$. The previous study demonstrated that miR-139 was downregulated in HCC and could serve as a diagnostic and prognostic marker for HCC (8); however, the major targets and precise signaling pathways that miR-139 participates in in HCC are not fully understood. A number of studies determined that overexpression of miR-139 suppresses the proliferation, invasion and metastasis of HCC cell lines in vitro (9-11). miR-139 is also associated with the functions of particular genes; it is reported that miR-139 may target transcription factor 4 (TCF-4) 3'-UTR, regulate the expression of TCF-4 and inhibit the $\beta$-catenin/TCF-4 pathway in HCC cell lines (9). Wong et al (11) reported that miR-139 reduces the expression of Rho-kinase 2 (ROCK2) in HCC cell lines. $c$-fos may be another downstream gene responsible for the metastatic effect in HCC cell lines. Furthermore, miR-139 is also identified as one of the post-hepatectomy recurrence-associated miRNAs (12). The expression of zinc finger E-box binding homeobox 1 (ZEB1) and ZEB2 was also inhibited by miR-139 through recognizing the 3'-UTR of these two genes (13). Considering that miRNAs serve a crucial role in multiple genes' expression and transcription regulation, it was hypothesized that miR-139 may have a major functional target gene and possibly acts as a key regulator of HCC progression.

In the present study, a combinational analysis of the data from four miRNA target prediction tools and biological experiments was applied to explore potential targets of 
tumor-suppressive miR-139 in HCC. It was demonstrated that Topoisomerase I (TOP1) is a proven, direct target of miR-139 in HCC. Overexpression of miR-139 inhibits HCC cell proliferation and migration, largely due to TOP1 downregulation. The present study indicated that miR-139 exerts a tumor-suppressive effect during hepatocarcinogenesis via suppressing the expression of TOP1; therefore, miR-139 is not only a biomarker for diagnosis and prognosis but also a promising target for the biological treatment of HCC.

\section{Materials and methods}

Bioinformatics analysis of miRNA target prediction. The majority of model organisms have an miRNA target gene prediction database, including TargetScan (http://www.targetscan. org/) (14), miRanda (http://www.microrna.org/) (15), miRDB (http://www.mirdb.org/) (16) and CLIP-Seq (http://www.starbase.sysu.edu.cn/) (17). Through these databases, an analysis of miR-139 was performed using bioinformatics in HCC. Using the combinational analysis of the data from four miRNA target prediction tools, four groups of genes were selected from the database and were identified as screening objects.

Cell culture. Human liver cancer cell lines BEL-7404 and SMMC-7721 were obtained from the Type Culture Collection of the Chinese Academy of Sciences (Shanghai, China). BEL-7404 and SMMC-7721 were maintained in RPMI-1640 medium (GE Healthcare Life Sciences, Logan, UT, USA) supplemented with $10 \%$ fetal bovine serum (FBS; Hyclone; GE Healthcare Life Sciences). HEK-293 was maintained in DMEM (GE Healthcare Life Sciences) supplemented with $10 \%$ FBS. The cells were incubated at $37^{\circ} \mathrm{C}$ in a humidified atmosphere containing $5 \% \mathrm{CO}_{2}$.

Cell transfection. BEL-7404 and SMMC-7721 cells were transfected with either miRNA mimics/inhibitors or plasmids using HiPerFect Transfection Reagent (Qiagen GmbH, Hilden, Germany), following the manufacturer's protocol. The miRNA mimics were chemically synthesized, double-stranded RNAs that mimic mature endogenous miRNAs following transfection into cells, whereas the miRNA inhibitors were chemically modified antisense RNA oligonucleotides optimized to specifically target specific miRNA molecules in cells. miRNA mimics, inhibitors and negative control (NC) sequences were chemically synthesized by Shanghai GenePharma Co., Ltd., (Shanghai, China). miR-139-NC: 5'-ACGUGACACGUUCGG AGAAUU3', miR-139 mimics: 5'-UCUACAGUGCACGUG UCUCCAGU-3' and miR-139 inhibitors: 5'ACUGGAGAC ACGUGCACUGUAGA-3'.

The reference miR-139 ID was MIMAT0000250 and the gene sequence was 5'-UCUACAGUGCACGUGUCU CCAGU-3'. miRNAs and/or DNA plasmids were diluted in Opti-MEM I reduced serum medium (Thermo Fisher Scientific, Inc., Waltham, MA, USA).

Briefly, the day prior to transfection, BEL-7404 and SMMC-7721 cells $\left(2 \times 10^{4}\right)$ were plated with medium of $100 \mu 1$ DMEM medium containing $10 \%$ FBS, placed in an incubator with $5 \% \mathrm{CO}_{2}$ at $37^{\circ} \mathrm{C}$. Transfection were performed when the cells were at $70-80 \%$ confluency and recorded as time 0 . Recombination plasmidTOP1 (ShanghaiGenePharmaCo.,Ltd.)
$(0.1 \mu \mathrm{g})$ was added, and/or $0.5 \mu 120 \mu \mathrm{M}$ miR-139 mimics or inhibitors were added to Opti-MEM for a final volume of $10 \mu \mathrm{l}$. Subsequently, $0.4 \mu \mathrm{l}$ Lipofectamine 2000 was added and the mixture were kept at room temperature for $15 \mathrm{~min}$. Following this, the transfection mixture was added to each cell medium and mixed. The media were changed to RPMI-1640 medium supplemented with $10 \%$ FBS following incubation in the incubator with $5 \% \mathrm{CO}_{2}$ at $37^{\circ} \mathrm{C}$ for $5 \mathrm{~h}$. Subsequently, the supernatant medium was removed following another incubation in an atmosphere containing $5 \% \mathrm{CO}_{2}$ at $37^{\circ} \mathrm{C}$ for $48 \mathrm{~h}$. Following this, the Passive Lysis Buffer (100 $\mu \mathrm{l}$; Promega Corporation, Madison, WI, USA) were added and the cells were lysed and collected following the mixture being shaken gently at room temperature for $15 \mathrm{~min}$. The cells were then collected for other subsequent experiments.

Immunoblotting. Total cell lysates were obtained using a Triton X-100 lysis buffer [20 mM Tris (pH 7.5), $150 \mathrm{mM}$ $\mathrm{NaCl}, 1 \mathrm{mM}$ EDTA, 1 mM EGTA, 1\% Triton X-100, $2.5 \mathrm{mM}$ Sodium pyrophosphate, $1 \mathrm{mM} \beta$-glycerophosphate and $1 \mathrm{mM}$ $\mathrm{Na}_{3} \mathrm{VO}_{4}$, supplemented with a protease inhibitor cocktail (Roche Applied Science, Penzberg, Germany) and phenylmethane sulfonyl fluoride $(1 \mathrm{mM})$, and determined with the BCA Protein Quantification kit (cat. no. BL521A; BioSharp, Hefei, China), according to the manufacturer's protocols.

Protein samples $(20 \mu \mathrm{g})$ were separated respectively by 12,10 and $8 \%$ SDS-PAGE, according to the following groups, which were divided by the protein molecular weight: BTG family member 3 (BTG3; 29 kDa); Casitas B-lineage lymphoma-transforming sequence-like protein 1 (CBLL1; 55 kDa); H2A Histone Family Member V (H2AFV; $14 \mathrm{kDa})$; Heterogeneous Nuclear Ribonucleoprotein $\mathrm{F}$ (HNRNPF; 46 kDa); Ligand Dependent Nuclear Receptor Corepressor (LCOR; 47 kDa); LIM Domain Only 4 (LMO4; $18 \mathrm{kDa}$ ); Protein Phosphatase 2 Catalytic Subunit Alpha (PPP2CA; $34 \mathrm{kDa}$ ), and $\beta$-actin (42 kDa) were separated by $12 \%$ SDS-PAGE; Mannosyl (Alpha-1,3-)-Glycoprotein Beta-1,4-N-Acetylglucosaminyltransferase, Isozyme A (MGAT4A; 62 kDa); Discoidin, CUB And LCCL Domain Containing 2 (DCBLD2; $78 \mathrm{kDa}$ ) and Intestinal Cell Kinase (ICK; $71 \mathrm{kDa}$ ) were separated by $10 \%$ SDS-PAGE; Eukaryotic Translation Initiation Factor 4 Gamma 2 (EIF4G2; 102 kDa); DNA Topoisomerase I (TOP1; $91 \mathrm{kDa}$ ) and Zinc Finger And BTB Domain Containing 10 (ZBTB10; 95 kDa) were separated by $8 \%$ SDS-PAGE) and were transferred onto polyvinylidene fluoride membranes for western blotting. The membranes were blocked with 5\% BSA (Solarbio Life Science, Beijing, China) at room temperature for $1 \mathrm{~h}$, then probed with primary antibodies [anti-BTG3, (dilution, 1:500; cat. no. bs-7698R; BIOSS, Beijing, China); anti-H2AFV, (dilution, 1:200; cat. no. bs-17425R; BIOSS); anti-HNRNPF (dilution, 1:500; cat. no. bs-4205R; BIOSS); anti-ICK, (dilution, 1:1,000; cat. no. bs-15536R; BIOSS); anti-LCOR, (dilution, 1:200; cat. no. bs-18198R; BIOSS); anti-ZBTB10, (dilution, 1:1,000; cat. no. bs-13556R; BIOSS); anti-LMO4, (dilution, 1:1,000; cat. no. bs-5966R; BIOSS); anti-PPP2CA, (dilution, 1:1,000; cat. no. bs-0029R; BIOSS); anti-EIF4G2 (dilution, 1:500; cat. no. bs-1350R; BIOSS); anti-DCBLD2 (dilution, 1:500; cat. no. bs-5834R; BIOSS); anti-MGAT4A (dilution, 1:1,000; cat. no. bs-18907R; BIOSS); anti-TOP1 (dilution, 1:1,000; 
A

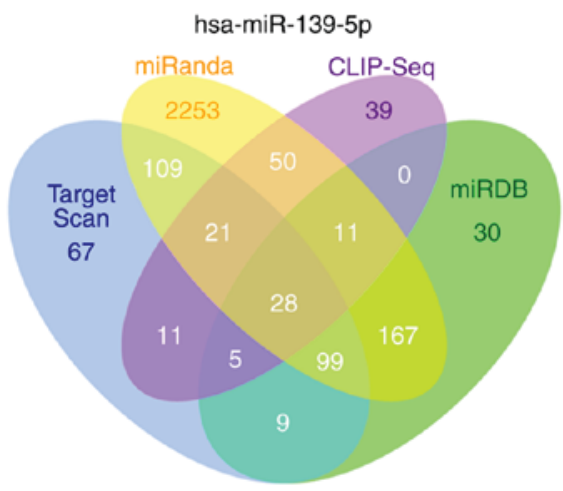

B

$\begin{array}{lclrr}\text { AEBP2 } & \text { AP3M1 } & \text { ATP5G3 } & \text { BTBD3 } & \text { BTG3 } \\ \text { CBLL1 } & \text { DCBLD2 } & \text { EIF4G2 } & \text { FAM76B } & \text { FBN2 } \\ \text { GDE1 } & \text { H2AFV } & \text { HNRNPF } & \text { ICK } & \text { KBTBD2 } \\ \text { KLHL28 } & \text { LCOR } & \text { LMO4 } & \text { LRCH2 } & \text { MGAT4A } \\ \text { NDFIP1 } & \text { PPP2CA } & \text { SLC25A3 } & \text { TOP1 } & \text { TSPAN3 } \\ \text { YWHAG } & \text { ZBTB10 } & \text { ZBTB34 } & & \end{array}$

Figure 1. Bioinformatics prediction of miR-139 targets. (A) A schematic diagram of miR-139 target prediction by four frequently used algorithms (TargetScan, miRanda, miRDB and CLIP-Seq). (B) Potential targets of miR-139 by intersecting the results predicted by all four algorithms. Genes reported to be aberrantly expressed in human cancers are marked in red.

cat. no. bs-10542R; BIOSS); anti-CBLL1 (dilution, 1:1,000; cat. no. bs-8386R; BIOSS,) and anti- $\beta$-actin, (dilution, 1:2,000; cat. no. 60008-1-Ig; Proteintech, Thermo Fisher Scientific, Inc.) overnight at $4^{\circ} \mathrm{C}$. The supernatants were removed and the membranes were washed by TBS with $0.1 \%$ Tween 20 (TBST) for $5 \mathrm{~min}$ three times. Subsequently, the anti-rabbit secondary antibodies (1:5,000; cat. no. ZB-2301; OriGene Technologies, Inc., Beijing, China) labeled with horseradish peroxidase (HRP) were added, and incubated at room temperature for $1 \mathrm{~h}$. Following this, the supernatants were removed and the membranes were washed with TBST three times, 5 mins per time. Finally, the blots were visualized by Trident femto Western HRP Substrate (GeneTex Inc.) and the images were captured using ChemiDocEQ detection system (Bio-Rad Laboratories, Hercules, California, USA.

Luciferase reporter assay. Cells of 50-90\% confluence in 48-well plates were transfected using Lipofectamine ${ }^{\circledR} 2000$ (Invitrogen; Thermo Fisher Scientific, Inc.). 3'-UTR of TOP1 gene was transfected with the vector psicheck 2.0 (Shanghai GenePharma Co., Ltd.) contained luciferase reporter gene. A total of $100 \mathrm{ng}$ of TOP1-transfected plasmid and a Renilla luciferase construct (5 ng; for normalization) were co-transfected in to the cells. Cell extracts were prepared $48 \mathrm{~h}$ after transfection, and the luciferase activity was measured using the Dual-Luciferase Reporter Assay System (Promega Corporation).

Cell proliferation assay. Cell proliferation assays were performed using the Cell Counting Kit-8 (Sigma-Aldrich; Merck KGaA, Darmstadt, Germany). Cells transfected with miR-139-NC were set as the negative control. The experiments were repeated three times. BEL-7404 and SMMC-7721 were seeded in 96-well plates at $\sim 5 \times 10^{3}$ cells/well and cultured in RPMI-1640 medium (GE Healthcare Life Sciences) supplemented with 10\% FBS (Beyotime Institute of Biotechnology, Shanghai, China). After $24 \mathrm{~h}, 15 \mu \mathrm{l}$ CCK-8 solution was added to each well and they were incubated at $37^{\circ} \mathrm{C}$ in $5 \% \mathrm{CO}_{2}$ for $3 \mathrm{~h}$. The absorbance was quantified at $492 \mathrm{~nm}$ by a microplate spectrophotometer (Thermo MK3; Thermo Fisher Scientific, Inc.).

Wound-healing assay. BEL-7404 and SMMC-7721 were maintained in RPMI-1640 medium (GE Healthcare Life
Sciences) supplemented with 10\% FBS (Beyotime Institute of Biotechnology). The cells were seeded onto six-well dishes at $2 \times 10^{5}$ cells/well. A single scratch wound was created in confluent cells using a p10 micropipette tip. Cells were washed twice with PBS to remove cell debris. Monitored images were captured by fluorescence microscopy (magnification, x400) (IX71; Olympus Corporation, Tokyo, Japan) at 0 and $24 \mathrm{~h}$ following wounding.

miRNA target prediction. To define potential downstream targets of miR-139, candidate genes that were commonly predicted were matched by four publicly available algorithms: TargetScan version 7.0, miRanda version 2010, miRDB and CLIP-Seq version 2.

Statistical analysis. Statistical analysis was performed using SPSS 11.0 for Windows (SPSS, Inc., Chicago, IL, USA). All data are presented as the mean \pm standard deviation. A two-tailed Student's t-test was used to evaluate the statistical significance of differences between two groups of data in the luciferase, cell proliferation and wound-healing assays. $\mathrm{P}<0.05$ was considered to indicate a statistically significant difference.

\section{Results}

Prediction of miR-139 targets. To identify the potential targets of tumor-suppressive miR-139 in HCC cells, a bioinformatics analysis was performed using miRNA target prediction tools. Computational predictions indicate that all human genes may be regulated by microRNAs, with each microRNA possibly targeting thousands of genes (18). As depicted in Fig. 1A, the four frequently used algorithms [TargetScan (14), miRanda (15), miRDB (16) and CLIP-Seq (17)] produced divergent sets of predicted targets of miR-139. To reduce bias caused by one method, the results predicted by the different algorithms were intersected and it was determined that a group of 28 genes are jointly identified by all four algorithms (Fig. 1). Some of these genes include: BTG3; CBLL1; DCBLD2; EIF4G2; H2AFV; HNRNPF; ICK; LCOR; LMO4; MGAT4A; PPP2CA; TOP1; and ZBTB10. These genes are reported to be aberrantly expressed in various cancer types and thus became a focus (Fig. 1B). 
A

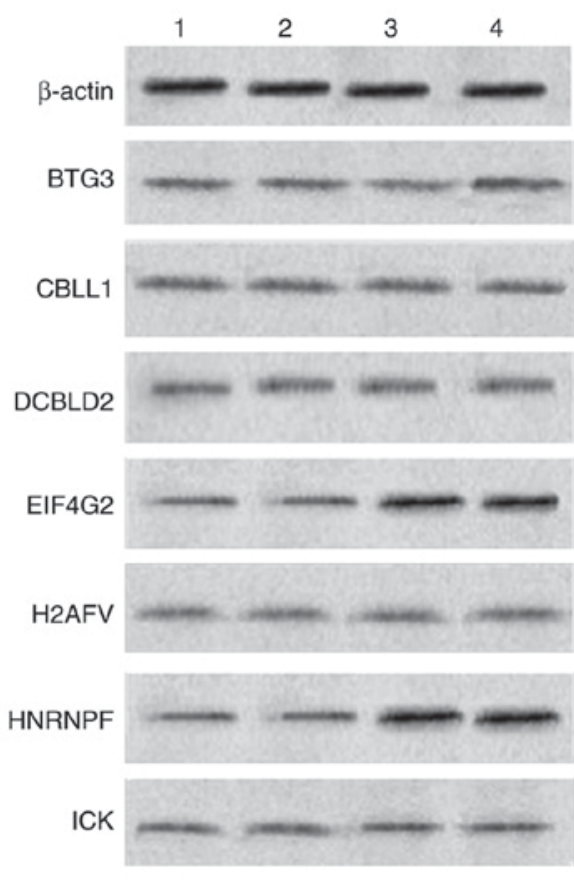

1: Mock

3: miR-139 mimics

8
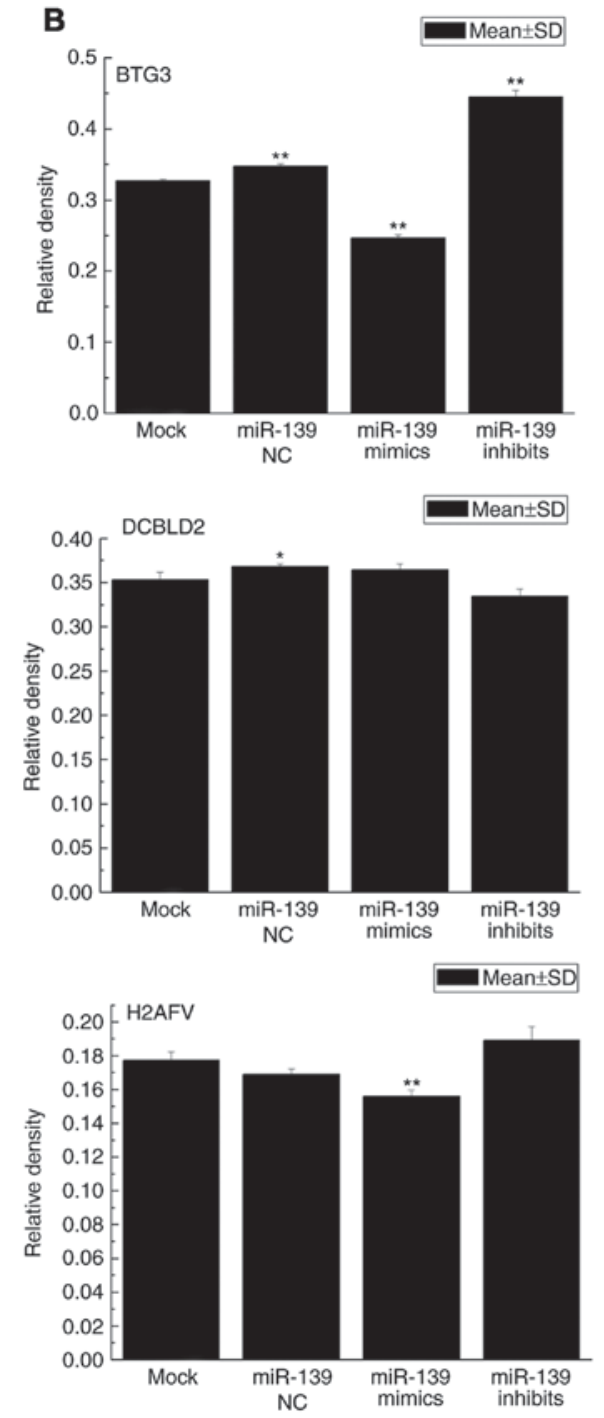

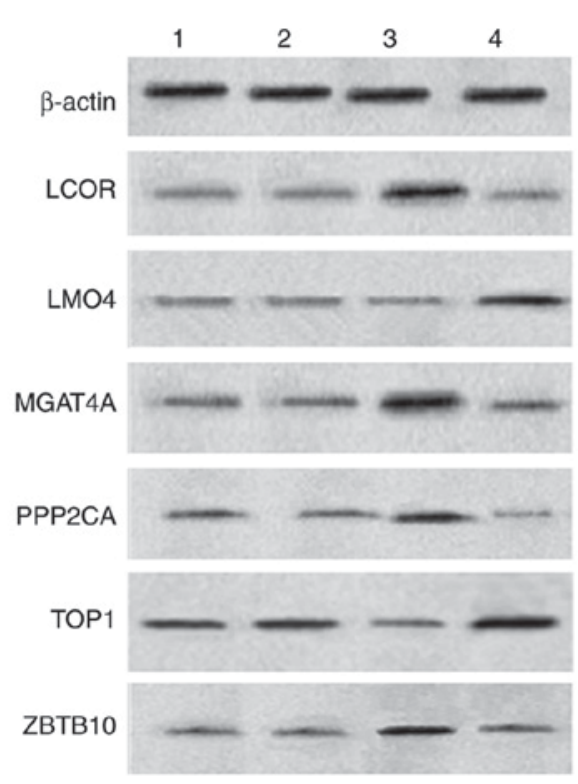

2: $\mathrm{miR}-139 \mathrm{NC}$

4: miR-139 inhibits
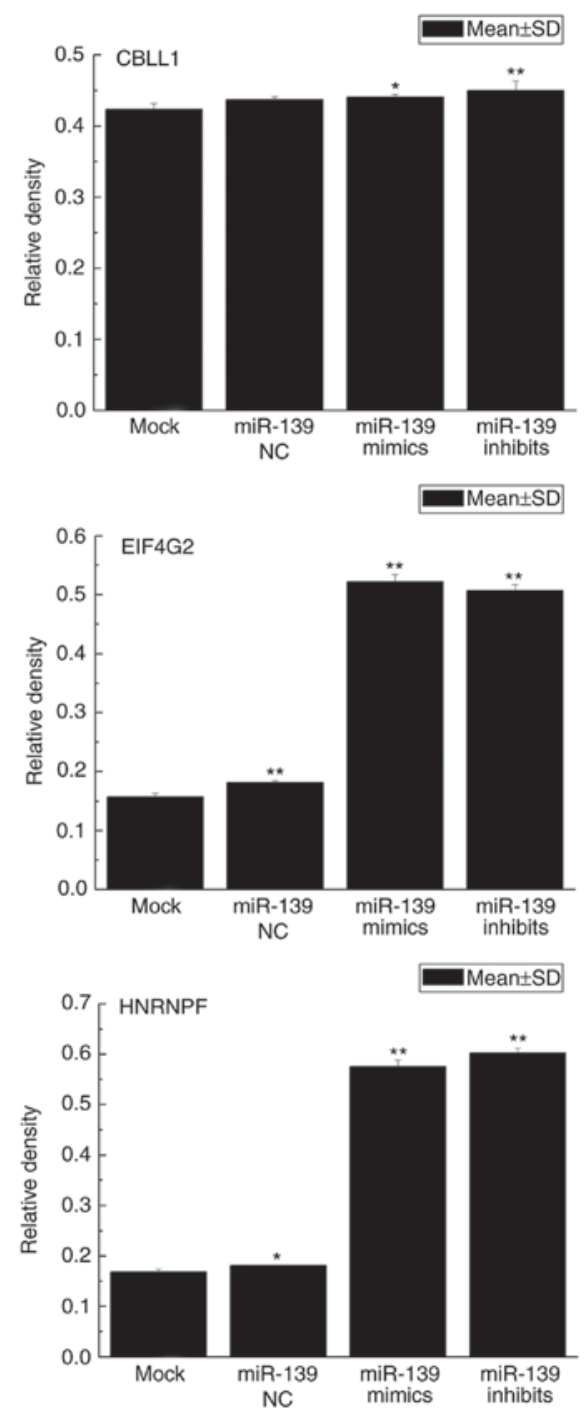

Figure 2. (A) miR-139 target screening by western blot analysis. (B) BEL-7404 cells were transfected with miR-139 mimics, miR-139 inhibitors or a negative control for $48 \mathrm{~h}$. Endogenous $\beta$-actin was used as an internal control for protein loading. 

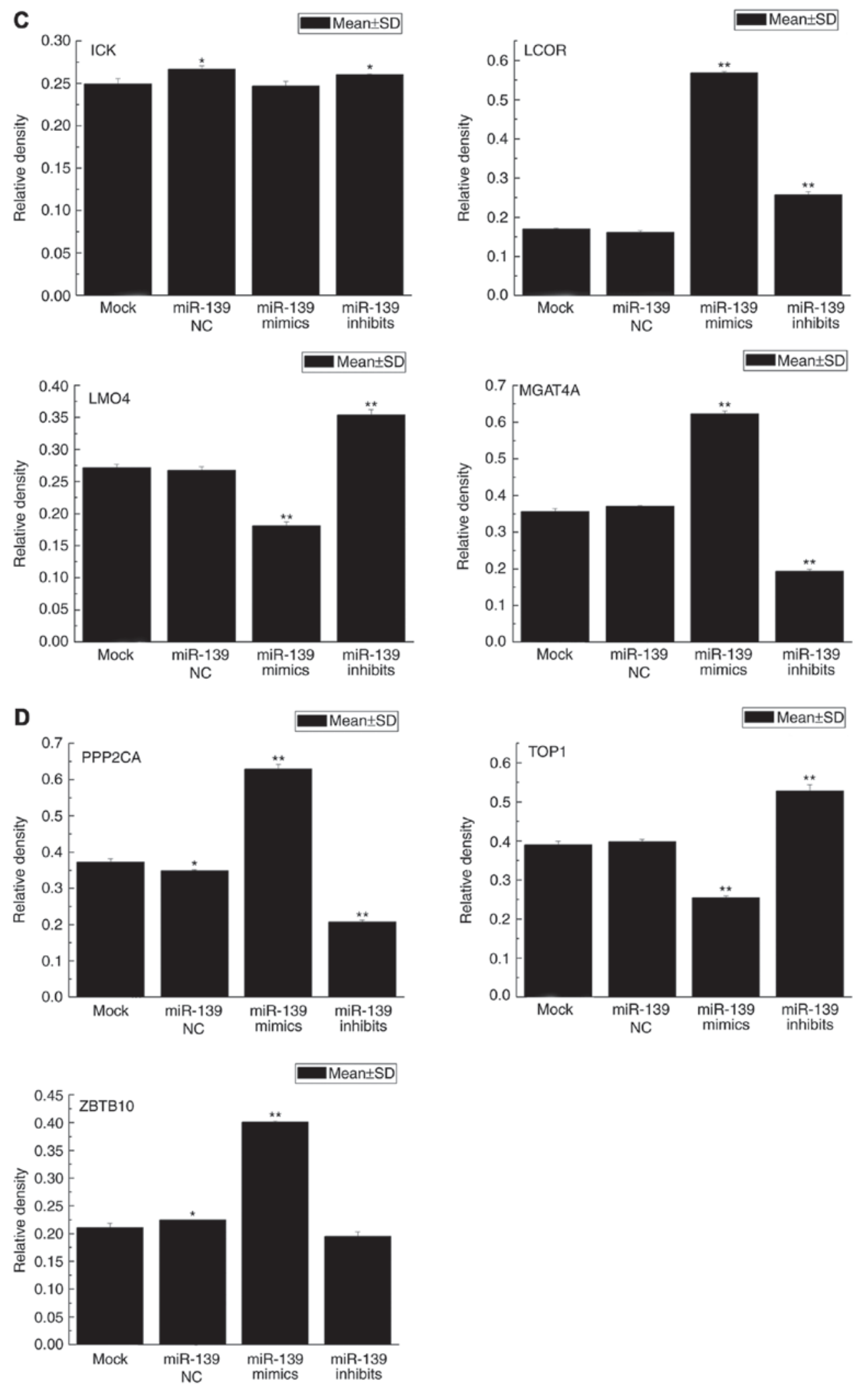

Figure 2. Continued. (C and D) BEL-7404 cells were transfected with miR-139 mimics, miR-139 inhibitors or a negative control for $48 \mathrm{~h}$. Endogenous $\beta$-actin was used as an internal control for protein loading. miRNA, microRNA; NC, negative control; SD, standard deviation. ${ }^{*} \mathrm{P}<0.05$ and ${ }^{* *} \mathrm{P}<0.01$.

miR-139 target screening by western blot analysis. To validate the potential targets of miR-139 in HCC cells, western blot analysis was performed to screen the predicted genes that are dysregulated in cancer. Two frequently used HCC cell lines, BEL-7404 and SMMC-7721, were selected and
miR-139 mimics, miR-139 inhibitors or a negative control were transfected into these cells. Following $48 \mathrm{~h}$, cells were lysed, and all samples were analyzed via semi-quantitative immunoblotting. As depicted in Figs. 2 and 3, increased miR-139 expression notably reduced TOP1 protein levels 


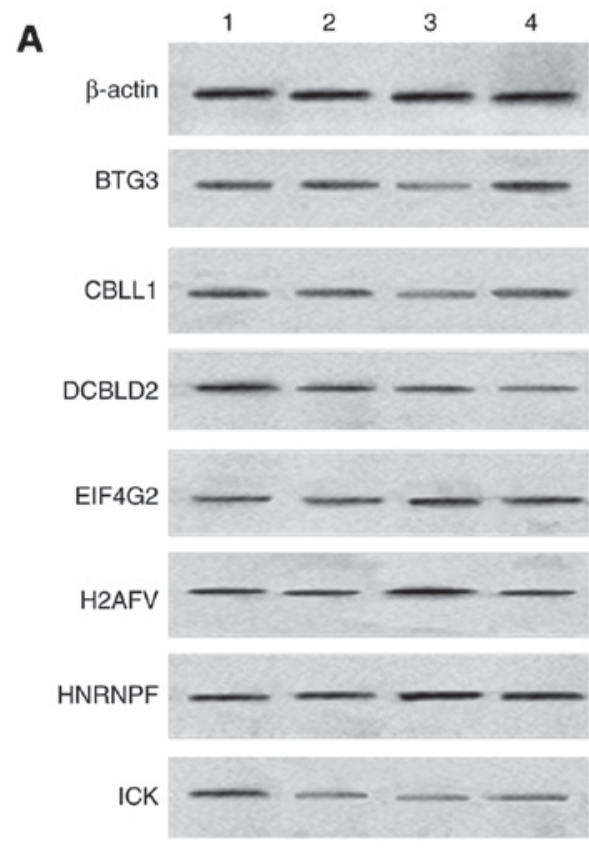

1: Mock

3: miR-139 mimics
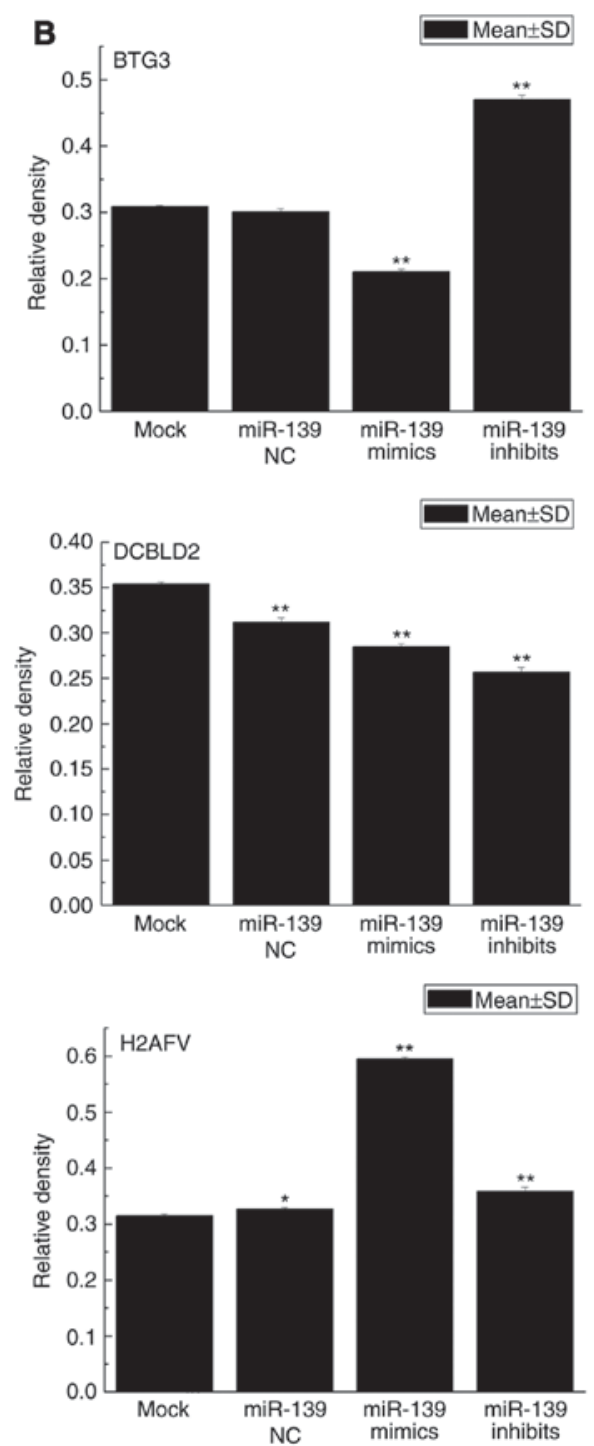

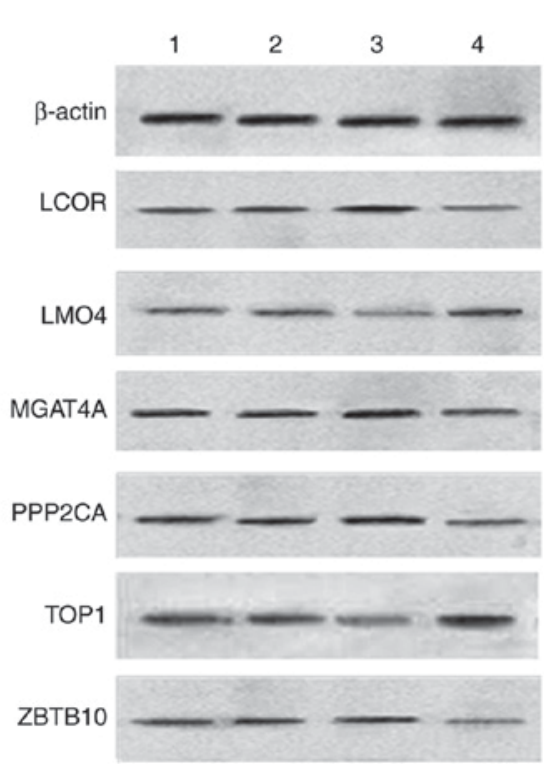

2: $\operatorname{miR}-139$ NC

4: miR-139 inhibits
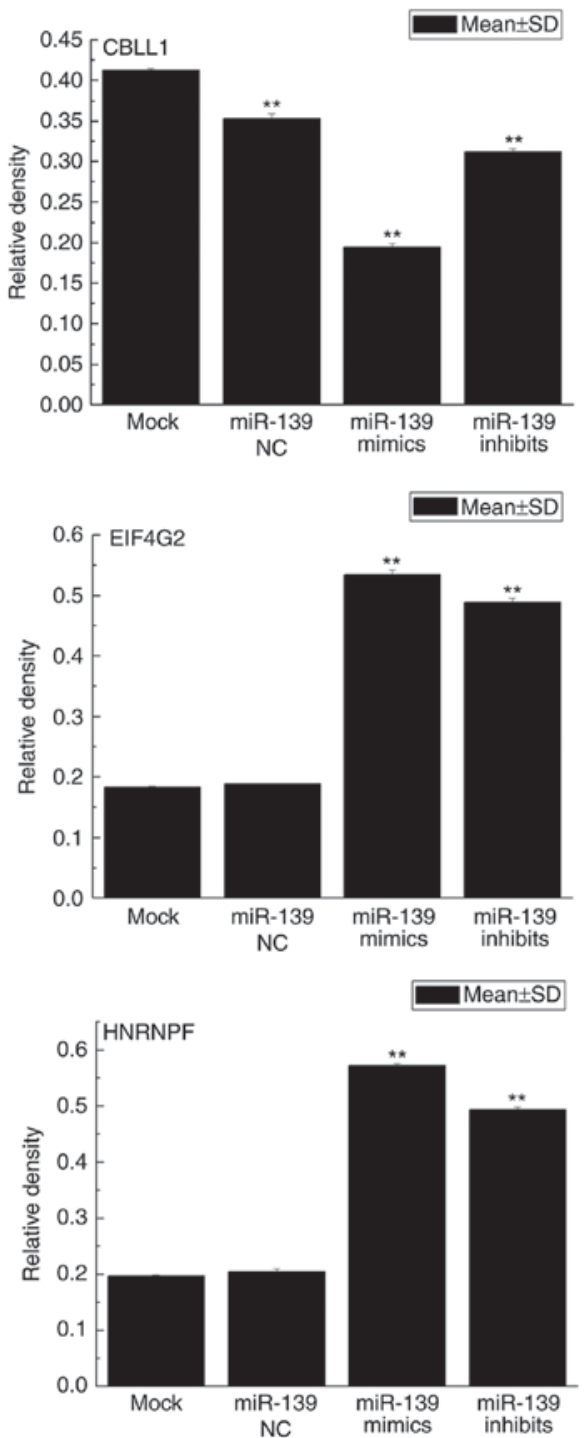

Figure 3. (A) miR-139 target screening by western blot analysis. (B) SMMC-7721 cells were transfected with miR-139 mimics, miR-139 inhibitors or a negative control for $48 \mathrm{~h}$. Endogenous $\beta$-actin was used as an internal control for protein loading. ${ }^{*} \mathrm{P}<0.05$ and ${ }^{* *} \mathrm{P}<0.01$. 


\section{C}
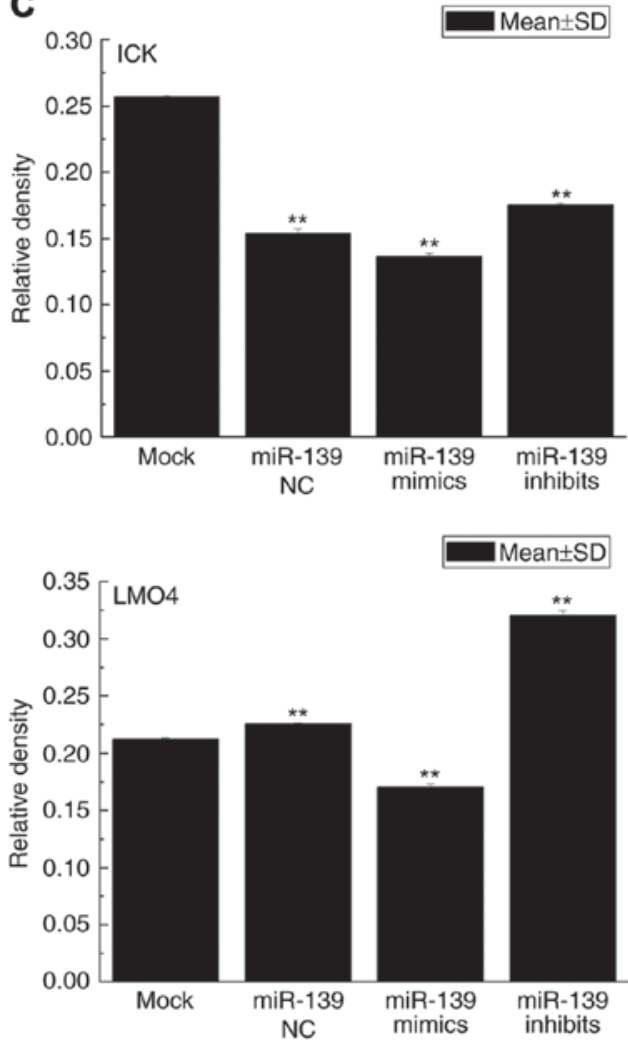

D

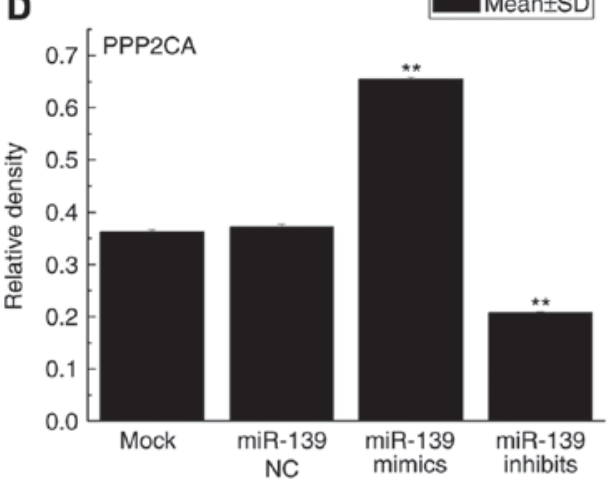

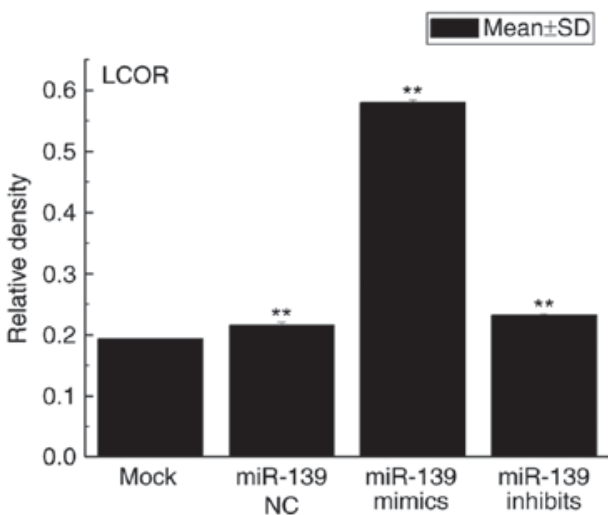
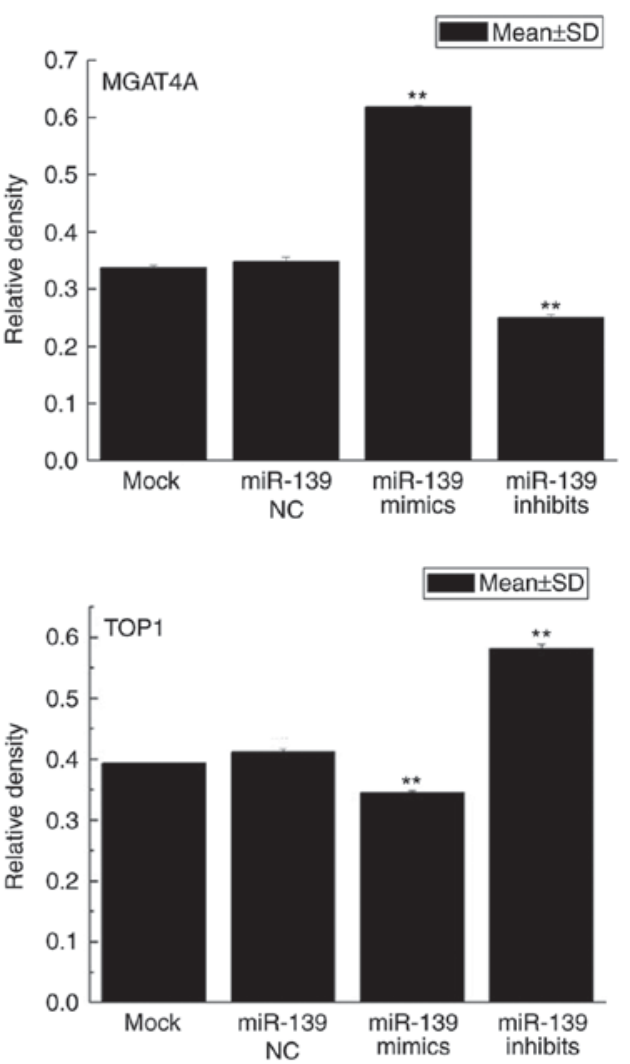

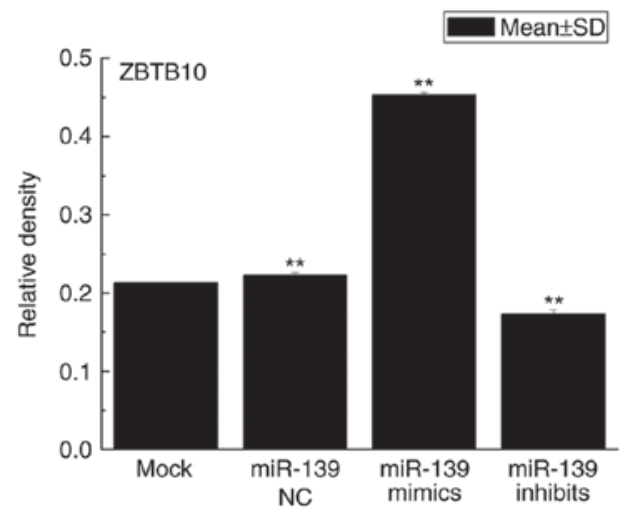

Figure 3. Continued. (C and D) SMMC-7721 cells were transfected with miR-139 mimics, miR-139 inhibitors or a negative control for $48 \mathrm{~h}$. Endogenous $\beta$-actin was used as an internal control for protein loading. miRNA, microRNA; NC, negative control; SD, standard deviation. ${ }^{*} \mathrm{P}<0.05$ and ${ }^{* *} \mathrm{P}<0.01$.

in both HCC cell lines, whilst miR-139 inhibitors had an opposite effect on TOPI expression. These results indicated that miR-139 could negatively regulate $T O P 1$ expression in HCC cells.
miR-139 directly targets and inhibits TOPI expression. As western blot analyses could not discriminate between direct and indirect effects of miR-139 on TOPl expression, a Dual-Luciferase reporter analysis was performed to determine 

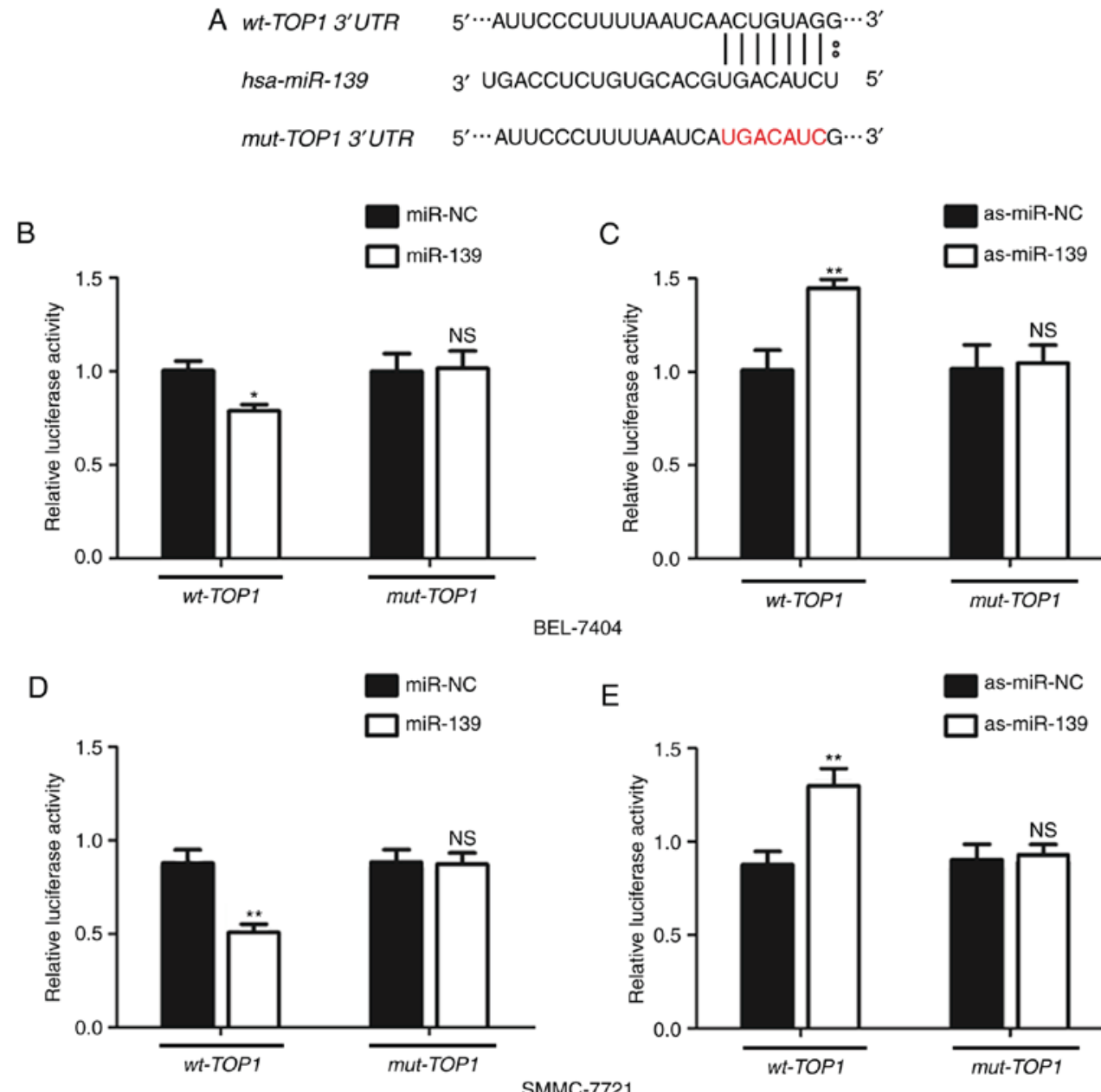

BEL-7404
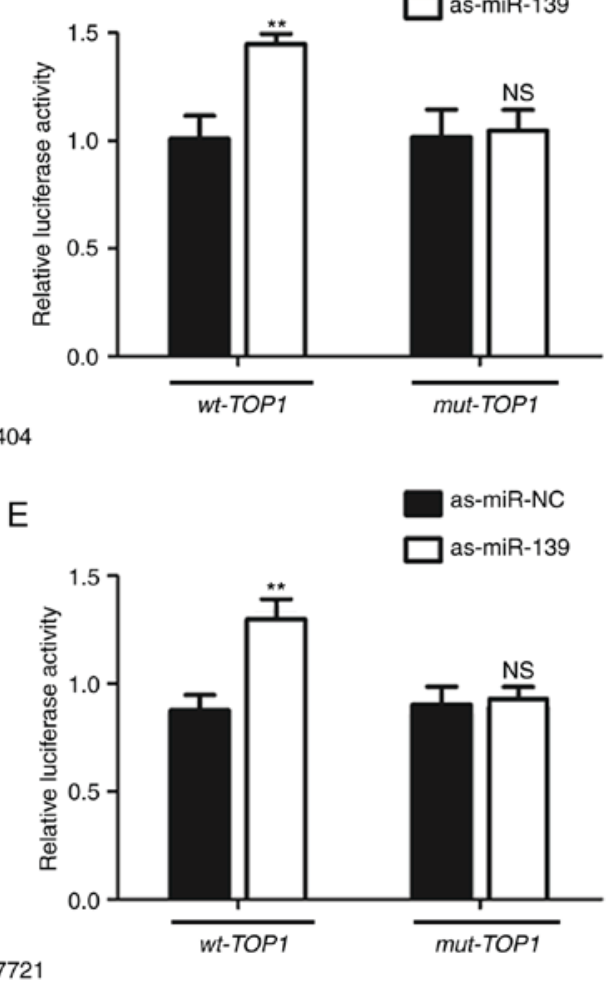

Figure 4. miR-139 directly targets and inhibits TOP1 expression. (A) Schematic representation of the putative miR-139 binding site in the 3'-UTR of TOP1 mRNA. Mutations were generated in the miR-139 binding site of the TOP1 3'-UTR (indicated in red). (B) Relative luciferase activity (mean \pm SD) mediated by reporter constructs harboring the wt or mut 3'-UTR of TOP1 upon transfection with $100 \mathrm{nM}$ miR-NC or miR-139 in BEL-7404 cells. (C) Relative luciferase activity (mean $\pm \mathrm{SD}$ ) mediated by reporter constructs harboring the wt or mut 3'-UTR of TOP1 upon transfection with $100 \mathrm{nM}$ miR-139 inhibitors or a negative control in BEL-7404 cells. (D) Relative luciferase activity (mean \pm SD) mediated by reporter constructs harboring the wt or mut 3'-UTR of TOP1 upon transfection with $100 \mathrm{nM}$ miR-NC or miR-139 in SMMC-7721 cells. (E) Relative luciferase activity (mean $\pm \mathrm{SD}$ ) mediated by reporter constructs harboring the wt or mut 3'-UTR of TOP1 upon transfection with $100 \mathrm{nM}$ miR-139 inhibitors or a negative control in SMMC-7721 cells. wt, wild type; mut, mutant; UTR, untranslated region; TOP1, Topoisomerase I; miRNA, microRNA; SD, standard deviation. ${ }^{*} \mathrm{P}<0.05$ and ${ }^{* *} \mathrm{P}<0.01$.

if miR-139 targets TOP1 mRNA directly. The results demonstrated that miR-139 significantly repressed the luciferase activity of a reporter vector harboring the wild-type 3'-UTR of TOP1, whereas mutation of the putative miR-139-binding site in the 3'-UTR region abrogated the inhibitory effect of miR-139 (Fig. 4A, B and C). Similarly, inhibition of miR-139 significantly enhanced luciferase activity of the reporter vector harboring the wild-type 3'-UTR of TOP1, and this effect could be completely abolished by mutation of the miR-139-binding site (Fig. 4D and E). Taken together, these results indicate that miR-139 directly binds to the 3'-UTR region of TOPI and inhibits its expression in HCC cells.

miR-139 suppresses HCC cell proliferation and migration through downregulation of TOP1. The previous study demonstrated that miR-139 is significantly downregulated in HCC tissues and is an independent risk factor for reduced survival (8); however, the biological function of this tumor-suppressive miRNA is largely unknown. To determine if miR-139 affects HCC cell proliferation, BEL-7404

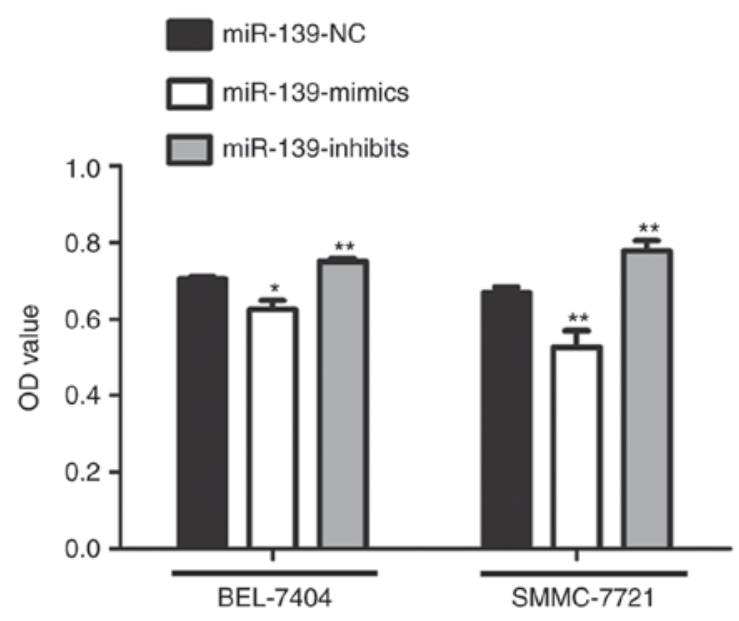

Figure 5. miR-139 suppresses HCC cell proliferation through downregulation of TOP1. BEL-7404 and SMMC-7721 cells were transfected with a negative control, miR-139 mimics or miR-139 inhibits overexpressing vectors for 48 h. Proliferation rates of HCC cells were determined by Cell Counting Kit-8 assay. OD, optical density; miRNA, microRNA; NC, negative control miRNA, microRNA; HCC, hepatocellular carcinoma. ${ }^{*} \mathrm{P}<0.05$ and ${ }^{* *} \mathrm{P}<0.01$. 
BEL-7404

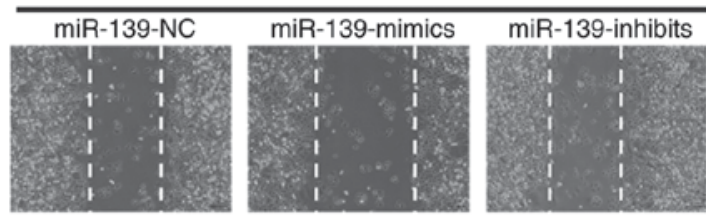

SMMC-7721

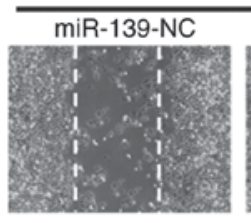

miR-139-mimics

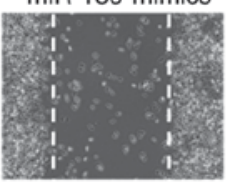
miR-139-inhibits

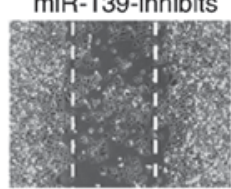

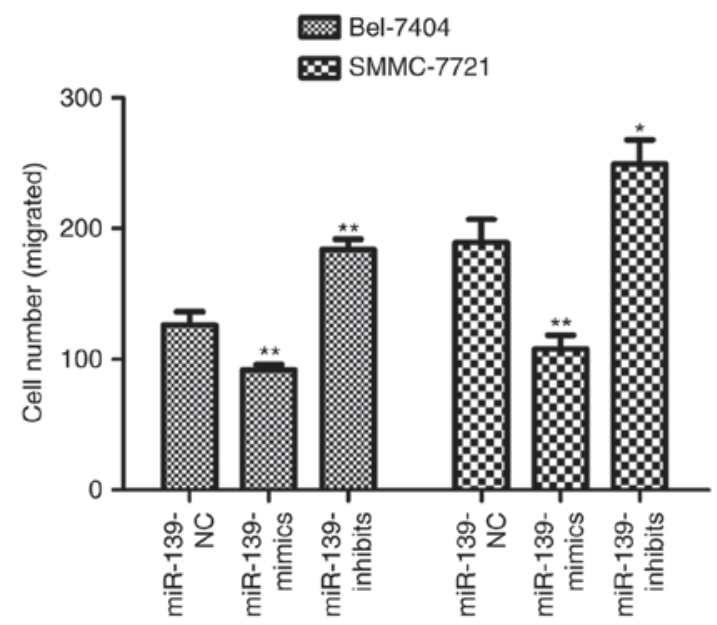

Figure 6. miR-139 suppresses hepatocellular carcinoma cell migration through downregulation of TOP1. BEL-7404 and SMMC-7721 cells were transfected with a negative control, miR-139 mimics or miR-139 inhibitor overexpressing vectors for $48 \mathrm{~h}$, and cell migration rates were determined by wound-healing assay. miRNA, microRNA; NC, negative control miRNA, microRNA. ${ }^{*} \mathrm{P}<0.05$ and ${ }^{* *} \mathrm{P}<0.01$.

and SMMC-7721 cells were treated with a negative control, miR-139 mimics or miR-139 inhibitors for 48 h. A CCK-8 assay demonstrated that enforced miR-139 expression significantly reduced the proliferation rate of both cell lines, whilst overexpression of TOP1 lacking the endogenous 3'-UTR completely abrogated the inhibitory effect of miR-139 (Fig. 5). Furthermore, a wound-healing assay was performed to test whether miR-139 had any effect on HCC cell migration. As depicted in Fig. 6, miR-139 overexpression notably repressed HCC cell migration, and miR-139-induced migration inhibition could be rescued by exogenous TOPI expression. Overall, these data indicated that tumor-suppressive miR-139 inhibits cell proliferation and migration through downregulation of TOPI in HCC.

\section{Discussion}

Since the beginning of this century, accumulating evidence has demonstrated that miRNAs serve pivotal roles in the process of tumorigenesis (19). An individual tumor type is characterized by a globally distinctive expression pattern of miRNAs (20-23) It has been demonstrated that miRNA expression patterns are closely associated with a number of important clinical events, including tumor diagnosis, treatment responses and prognosis $(24,25)$. Furthermore, novel evidence has revealed more specific roles of miRNA in tumorigenesis (26). A number of functional studies have demonstrated that miRNAs serve an oncogenic or tumor suppressor role in different malignancies, in vitro and in vivo (27). MiRNA-139 was determined to be dysregulated in various cancer types, including breast and colon cancer $(28,29)$, but the precise function of this miRNA still requires further exploration. Wong et al (11) determined that low expression of miR-139 is associated with metastatic HCC and overexpression of miR-139 suppresses metastasis and the progression of HCC by downregulating ROCK2 (11). In addition, a low-expression of miR-139 was also determined in colorectal cancer and breast cancer, which indicates that miR-139 may be a key regulator in malignancies $(11,28)$. The previous study demonstrated that miR-139 is significantly downregulated in HCC tissues and could be used as an independent risk factor for predicting prognosis in patients with HCC (8).

Development of dysplastic hepatocytes in point foci and nodules dysplasia and formation emergence in $\mathrm{HCC}$ are associated with the build-up of an accumulation of irreversible structural alterations in genes and chromosomes (3); therefore, identification of key genes that promote genomic instability is of great importance to cancer gene therapy. In the present study, TOP1 was identified as a direct target of miR-139 in HCC. DNA topoisomerases are vital enzymes that solve DNA topological problems that result from strand separation during replication and transcription. TOP 1 is a nuclear enzyme that cuts one of the two strands of DNA, relaxes the strand and reanneals the strand, thereby allowing moving DNA supercoils during DNA replication or gene transcription (30). Based on this function, topoisomerases are emerging as important factors in a wide range of fundamental biological processes in nuclear and mitochondrial genomes (31). Topoisomerases introduce transient DNA breaks using a transesterification mechanism, which is highly reversible and minimizes the risks of genome stability that would otherwise occur due to strand breakage (32); therefore, formation of a DNA-TOP1 complex is a crucial intermediate step in the transesterification mechanism. However, aberrant expression of TOPI is potentially hazardous to the cell due to it mediating an illegitimate recombination that may lead to genomic instability and oncogenesis (33). Therefore, it is now established that topoisomerases can ensure and endanger genome integrity. Kim et al (32) indicated that TOPI could provoke genome instability by action at sites of endogenous and exogenous DNA damage. The risks associated with strand breakage by topoisomerases indicate that there are aspects of fundamental processes, including transcription, that pose unique topological challenges and that cells require a wide repertoire of responses and specific repair pathways to safeguard the dangerous process of introducing transient DNA breaks. The importance of topoisomerases in genomic maintenance may also explain why cancer cells, which are high replicative and undergo transcriptional stress, frequently overexpress nuclear and mitochondrial topoisomerases (34). 
Furthermore, it has been determined that TOP1 is highly expressed in a number of malignancy types, including colon cancer and breast cancer $(35,36)$, indicating its potential role in tumorigenesis. The major effect of TOP1-induced DNA lesions on cell survival has resulted in this enzyme being a prime target for cancer therapies to kill fast-growing cancer cells (37). To date, a number of TOPI inhibitors have been developed, including camptothecins, irinotecan and topotecan. However, camptothecins and its water-soluble derivatives have several limitations. For example, camptothecins produce side effects (including leucopenia) that limit the dose that can be safely administered and, therefore, its anti-tumor efficacy (38). The diarrhea induced by irinotecan can be severe and is possibly due to 'off-target' effects that are associated with the bis-piperidine that confers water-solubility (38); therefore, novel therapeutic strategies targeting TOP1 are required to be developed by further increasing their antitumor activity and decreasing the side effects. However, miR-139 may be an alternative target for the same molecular signal pathway.

Due to the potential ability of miRNAs to influence multiple cellular behaviors, therapeutic strategies based on modulation of miRNA expression levels have demonstrated great promise (39). Recent studies indicated that enforced overexpression of individual miRNA exhibits a powerful antitumorigenic effect in lymphoma cells transformed by key oncogenes, including c-Myc and Bcl-2 (40). Furthermore, Kumar et al (40) demonstrated that systemic administration of viral vectors expressing let-7 miRNAs impaired tumor growth in a mouse model with lung adenocarcinoma. In the present study, it was reported that TOP1 is inhibited by a tumor-suppressive miRNA miR-139 and increased expression of miR-139 impairs HCC cell proliferation and migration. The present study indicated that miR-139 could be a promising novel therapeutic option for targeting TOP1 and holds great potential in the treatment of HCC. It was speculated that miR-139 may be a safe and effective TOP1 inhibitor with fewer side effects.

\section{Acknowledgements}

Not applicable.

\section{Funding}

This work was supported by Shaanxi Science and Technology Department (grant no. 2015KTCL03-05).

\section{Availability of data and materials}

The datasets used during the current study are available from the corresponding author on reasona-ble request. The raw data required to reproduce these findings cannot be shared at this time as the data also forms part of an ongoing study.

\section{Authors' contributions}

PZ and JY proposed the study and wrote the first draft and analyzed the data. LY, QW, XD, RD, GZ and JL conceived and improved the manuscript. CW, QB and LJ performed the experiments. GZ and JL analyzed the data and approved the final version to be published. All authors read and approved the manuscript.

\section{Ethics approval and consent to participate}

Not applicable.

\section{Patient consent for publication}

Not applicable.

\section{Competing interests}

The authors declare that they have no competing interests.

\section{References}

1. Torre LA, Bray F, Siegel RL, Ferlay J,Lortet-Tieulent J and Jemal A: Global cancer statistics, 2012. CA Cancer J Clin 65: 87-108, 2015.

2. Carr BI: Hepatocellular carcinoma: Current management and future trends. Gastroenterology 127: S218-S224, 2004.

3. Thorgeirsson SS and Grisham JW: Molecular pathogenesis of human hepatocellular carcinoma. Nat Genet 31: 339-346, 2002.

4. Garzon R, Calin GA and Croce CM: MicroRNAs in Cancer. Annu Rev Med 60: 167-179, 2009.

5. Bartel DP: MicroRNAs: Target recognition and regulatory functions. Cell 136: 215-233, 2009.

6. Murakami Y, Yasuda T, Saigo K, Urashima T, Toyoda H, Okanoue $\mathrm{T}$ and Shimotohno K: Comprehensive analysis of microRNA expression patterns in hepatocellular carcinoma and non-tumorous tissues. Oncogene 25: 2537-2545, 2006.

7. Calin GA and Croce CM: MicroRNA signatures in human cancers. Nat Rev Cancer 6: 857-866, 2006.

8. Li T, Yin J, Yuan L, Wang S, Yang L, Du X and Lu J: Downregulation of microRNA-139 is associated with hepatocellular carcinoma risk and short-term survival. Oncol Rep 31: 1699-1706, 2014.

9. Gu W, Li X and Wang J: miR-139 regulates the proliferation and invasion of hepatocellular carcinoma through the WNT/TCF-4 pathway. Oncol Rep 31: 397-404, 2014.

10. Hua S, Lei L, Deng L, Weng X, Liu C, Qi X, Wang S, Zhang D, Zou X, Cao C, et al: miR-139-5p inhibits aerobic glycolysis, cell proliferation, migration, and invasion in hepatocellular carcinoma via a reciprocal regulatory interaction with ETS1. Oncogene 37: 1624-1636, 2018

11. Wong CC, Wong CM, Tung EK, Au SL, Lee JM, Poon RT, Man K and Ng IO: The microRNA miR-139 suppresses metastasis and progression of hepatocellular carcinoma by down-regulating Rho-kinase 2. Gastroenterology 140: 322-331, 2011.

12. Wang L, Liu M, Zhu H, Rong W, Wu F, An S, Liu F, Feng L, Wu J and $\mathrm{Xu}$ N: Identification of recurrence-related serum microRNAs in hepatocellular carcinoma following hepatectomy. Cancer Biol Ther 16: 1445-1452, 2015.

13. Qiu G, Lin Y, Zhang H and Wu D: miR-139-5p inhibits epithelial-mesenchymal transition, migration and invasion of hepatocellular carcinoma cells by targeting ZEB1 and ZEB2. Biochem Biophys Res Commun 463: 315-321, 2015.

14. Lewis BP, Shih IH, Jones-Rhoades MW, Bartel DP and Burge CB: Prediction of mammalian microRNA targets. Cell 115: 787-798, 2003.

15. John B, Enright AJ, Aravin A, Tuschl T, Sander C and Marks DS: Human MicroRNA targets. PLoS Biol 2: e363, 2004.

16. Wong N and Wang X: miRDB: An online resource for microRNA target prediction and functional annotations. Nucleic Acids Res 43: D146-D152, 2015.

17. Croce CM: Causes and consequences of microRNA dysregulation in cancer. Nat Rev Genet 10: 704-714, 2009.

18. Ritchie W, Rasko JE and Flamant S: MicroRNA target prediction and validation. Adv Exp Med Biol 774: 39-53, 2013.

19. Volinia S, Calin GA, Liu CG, Ambs S, Cimmino A, Petrocca F, Visone R, Iorio M, Roldo C, Ferracin M, et al: A microRNA expression signature of human solid tumors defines cancer gene targets. Proc Natl Acad Sci USA 103: 2257-2261, 2006. 
20. Xie X, Tan W, Chen B, Huang X, Peng C, Yan S, Yang L, Song C, Wang J, Zheng W, et al: Preoperative prediction nomogram based on primary tumor miRNAs signature and clinical-related features for axillary lymph node metastasis in early-stage invasive breast cancer. Int J Cancer 142: 1901-1910, 2018.

21. Slattery ML, Lee FY, Pellatt AJ, Mullany LE, Stevens JR, Samowitz WS, Wolff RK and Herrick JS: Infrequently expressed miRNAs in colorectal cancer tissue and tumor molecular phenotype. Mod Pathol 30: 1152-1169, 2017.

22. Mannavola F, Tucci M, Felici C, Stucci S and Silvestris F: miRNAs in melanoma: A defined role in tumor progression and metastasis. Exp Rev Clin Immunol 12: 79-89, 2016.

23. Tian F, Li R, Chen Z, Shen Y, Lu J, Xie X and Ge Q: Differentially expressed miRNAs in tumor, adjacent, and normal tissues of lung adenocarcinoma. Biomed Res Int 2016: 1428271, 2016.

24. Lu J, Getz G, Miska EA, Alvarez-Saavedra E, Lamb J, Peck D, Sweet-Cordero A, Ebert BL, Mak RH, Ferrando AA, et al MicroRNA expression profiles classify human cancers. Nature 435: 834-838, 2005.

25. Wang L, Zhang X, Jia LT, Hu SJ, Zhao J, Yang JD, Wen WH, Wang Z, Wang T, Zhao J, et al: c-Myc-mediated epigenetic silencing of MicroRNA-101 contributes to dysregulation of multiple pathways in hepatocellular carcinoma. Hepatology 59: $1850-1863,2014$

26. Yu F, Yao H, Zhu P, Zhang X, Pan Q, Gong C, Huang Y, Hu X, Su F, Lieberman J and Song E: let-7 regulates self renewal and tumorigenicity of breast cancer cells. Cell 131: 1109-1123, 2007.

27. Shen K, Liang Q, Xu K, Cui D, Jiang L, Yin P, Lu Y, Li Q and Liu J: MiR-139 inhibits invasion and metastasis of colorectal cancer by targeting the type I insulin-like growth factor receptor. Biochem Pharmacol 84: 320-330, 2012.

28. Krishnan K, Steptoe AL, Martin HC, Pattabiraman DR, Nones K, Waddell N, Mariasegaram M, Simpson PT, Lakhani SR, Vlassov A, et al: miR-139-5p is a regulator of metastatic pathways in breast cancer. RNA 19: 1767-1780, 2013.

29. Ashour ME, Atteya $R$ and El-Khamisy SF: Topoisomerase-mediated chromosomal break repair: An emerging player in many games. Nat Rev Cancer 15: 137-151, 2015.
30. Stewart L, Redinbo MR, Qiu X, Hol WG and Champoux JJ: A model for the mechanism of human topoisomerase I. Science 279: 1534-1541, 1998

31. Pommier Y, Sun Y, Huang SN and Nitiss JL: Roles of eukaryotic topoisomerases in transcription, replication and genomic stability. Nat Rev Mol Cell Biol 17: 703-721, 2016.

32. Kim N, Huang SN, Williams JS, Li YC, Clark AB, Cho JE, Kunkel TA, Pommier Y and Jinks-Robertson S: Mutagenic processing of ribonucleotides in DNA by yeast topoisomerase I. Science 332: 1561-1564, 2011.

33. Larsen AK and Gobert C: DNA topoisomerase I in oncology: Dr Jekyll or Mr Hyde? Pathol Oncol Res 5: 171-178, 1999.

34. Rahman M, Jackson LK, Johnson WE, Li DY, Bild AH and Piccolo SR: Alternative preprocessing of RNA-sequencing data in the cancer genome atlas leads to improved analysis results. Bioinformatics 31: 3666-3672, 2015.

35. Kümler I, Balslev E, Stenvang J, Brünner N and Nielsen D: A phaseII study of weeklyirinotecanin patients withlocally advanced or metastatic HER2-negative breast cancer and increased copy numbers of the topoisomerase 1 (TOP1) gene: A study protocol. BMC Cancer 15: 78, 2015.

36. Giovanella BC, Stehlin JS, Wall ME, Wani MC, Nicholas AW, Liu LF, Silber R and Potmesil M: DNA topoisomerase I-targeted chemotherapy of human colon cancer in xenografts. Science 246 : 1046-1048, 1989.

37. Li M and Liu Y: Topoisomerase I in human disease pathogenesis and treatments. Genomics Proteomics Bioinformatics 14: 166-171, 2016.

38. Pommier Y: Topoisomerase I inhibitors: Camptothecins and beyond. Nat Rev Cancer 6: 789-802, 2006.

39. Sampson VB, Rong NH, Han J, Yang Q, Aris V, Soteropoulos P, Petrelli NJ, Dunn SP and Krueger LJ: MicroRNA let-7a down-regulates MYC and reverts MYC-induced growth in Burkitt lymphoma cells. Cancer Res 67: 9762-9770, 2007.

40. Kumar MS, Erkeland SJ, Pester RE, Chen CY, Ebert MS, Sharp PA and Jacks T: Suppression of non-small cell lung tumor development by the let-7 microRNA family. Proc Natl Acad Sci USA 105: 3903-3908, 2008. 